\title{
REASONS OF STRESS CORROSION FAILURE OF ERECTION GIRTH JOINT OF MAIN GAS PIPELINE
}

\author{
A.A. RYBAKOV ${ }^{1}$, L.V. GONCHARENKO ${ }^{1}$, T.N. FILIPCHUK ${ }^{1}$, I.V. LOKHMAN ${ }^{2}$ and I.Z. BURAK ${ }^{2}$ \\ ${ }^{1}$ E.O. Paton Electric Welding Institute, NASU \\ 11 Bozhenko Str., 03680, Kiev, Ukraine. E-mail: office@paton.kiev.ua \\ ${ }^{2}$ PJSC «Ukrtransgaz» \\ 9/1 Klovsky Spusk, 01021, Kiev, Ukraine. E-mail: press@utg.ua
}

\begin{abstract}
Considered are some issues of stress corrosion failure of metal of main gas pipeline under operation. It is shown that, except for conventional orientation of stress corrosion cracks in longitudinal direction, the defects of such a type can propagate in transverse direction relatively to axis of the gas pipeline. Found transverse stress corrosion cracks, including ones passing through the whole thickness of the pipe wall, were formed in a zone of girth weld, joining $1420 \mathrm{~mm}$ diameter pipes of K60 strength class. Defective zone of $800 \mathrm{~mm}$ length was located from both sides of the weld and propagated at approximately $60 \mathrm{~mm}$ width from fusion line. Failure surface in zone of defects has specific step nature as a result of coalescence of finer semi-elliptical cracks, nucleated in different planes being displaced relatively to each other. The cracks are mainly characterized by rounded tips, that is typical for stress corrosion defects, formed as a result of anode metal dissolution. Failure of girth welded joint of the pipeline, except for corrosion factors, was promoted, to significant extent, by additional stresses typical for process of pipe assembly during performance of «tie-in». Information of this paper can be used during performance of diagnostic operations on main pipelines.

7 Ref., 1 Table, 9 Figures.
\end{abstract}

$\boldsymbol{K} \boldsymbol{e} \boldsymbol{y} \boldsymbol{w} \boldsymbol{o} \boldsymbol{r} \boldsymbol{d}:$ stress corrosion failure, main gas pipeline, crack orientation, welded pipes, strength class, girth welded joint, reasons of formation

Today, stress corrosion cracking (SCC) of metal is one of the main and most frequent reasons of failure of main pipelines. Damages of such a type are the cracks formed on external surface of the pipelines in areas with failure of insulation coating under effect of corrosion-active media and stress-strain factor under conditions of cathode polarization.

Consequences of failure of the gas pipelines due to SCC (SCC-failure) are sufficiently impressive. Figure 1 shows, as an example, the trench and fragments of $820 \mathrm{~mm}$ diameter pipeline after SCC-failure spread at $40-50 \mathrm{~m}$.

Main external sign, used for determination of origin of cracks due to SCC (SC-cracks), is presence of colonies of cracks, oriented as a rule in longitudinal direction, on the external surface of the pipes. Work [1] studied different cases of the stress corrosion damages of main pipelines and preferred development of SC-cracks in the longitudinal direction was underlined, however, a possibility of curving of their orientation due to bend or shrinkage of gas pipeline (Figure 2) is noted. SC-cracks are found in a base metal as well as in a zone of pipeline joints welded at plant. In the most cases, they are detected in low part of the pipe section, close to longitudinal welds, including in a fusion line.

As is well-known, initial stage of stress corrosion damaging lies in formation of a corrosion pitting, which further transforms in the semi-elliptical cracks [2-4]. Conditions for joining (coa-

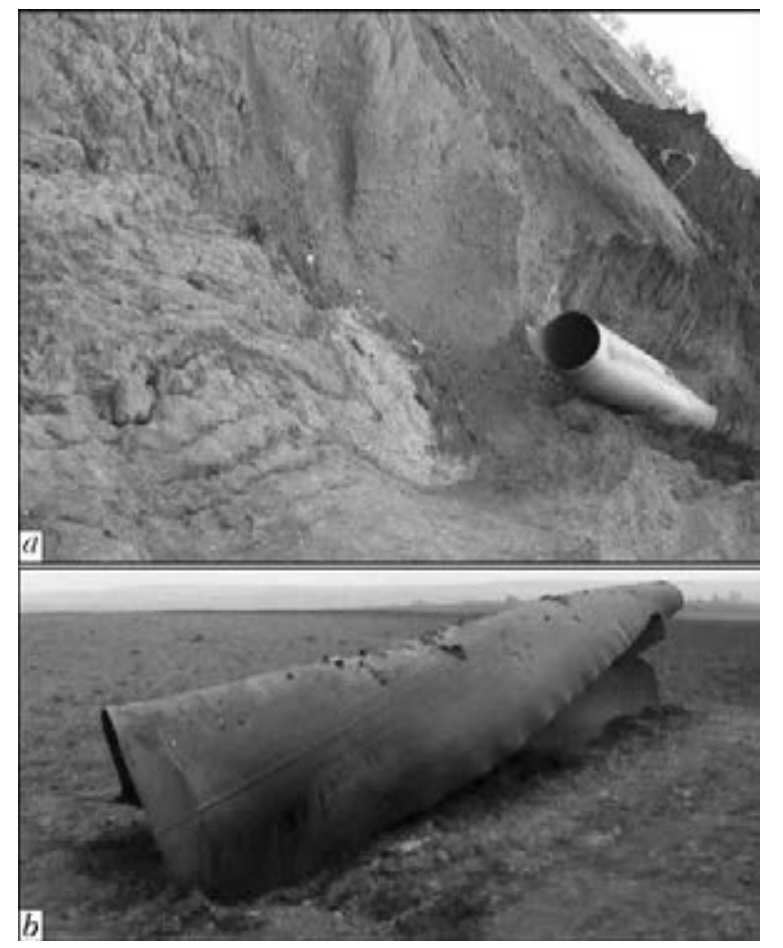

Figure 1. Stress corrosion failure of main gas pipeline of $820 \mathrm{~mm}$ diameter $(a)$ and fragments of failed pipes $(b)$ 


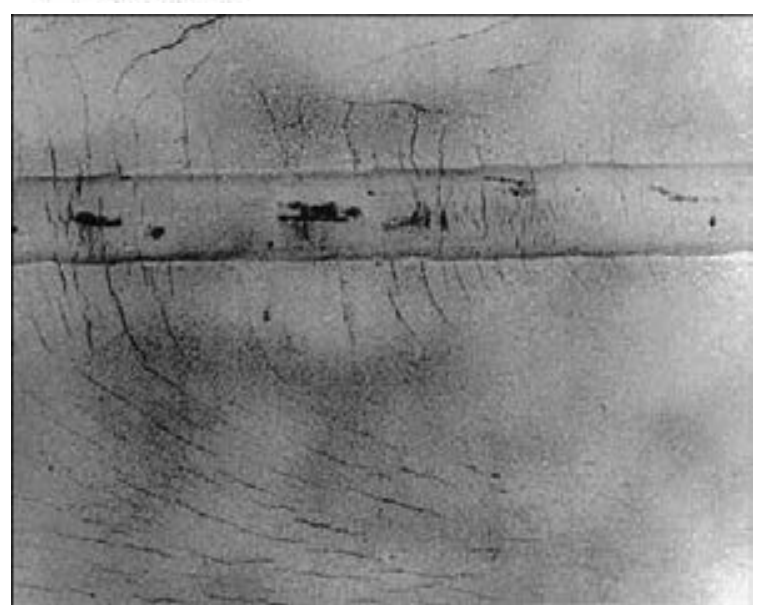

Figure 2. Effect of stress distribution in pipe metal on character of location of SC-cracks [1]

lescence) of neighbor, closely located cracks, formation of main crack and further failure of the gas pipeline are created in course of defect development.

In accordance to current representations, SCC can propagate on two mechanisms, namely local anode dissolution and hydrogen cracking [4-7]. If the first mechanism is realized, electro-chemical process is localized on the surface of metal and its intensive dissolution takes place in a crack tip. Such cracks, as a rule, are characterized by wider opening, presence of corrosion deposits and their tip has blunt form (Figure 3, a). In the second case, diffusion of hydrogen in a metal lattice is performed under effect of stresses and corrosion media. More acute tip, transcrystalline nature of propagation and some splitting ( $\mathrm{Fi}^{-}$ gure $3, b)$ are typical for the cracks of this type.

Several accident of the gas pipelines, caused by stress corrosion defects, took place in Ukraine. Figure 4 shows appearance and fracture of the

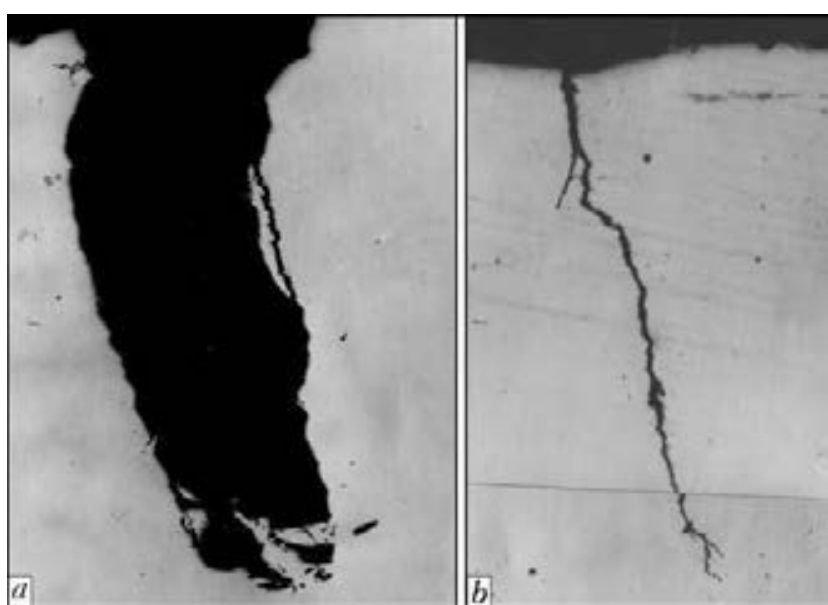

Figure 3. SC-cracks in metal of gas line pipe formed as a result of anode dissolution $(a-\times 20)$ and hydrogen cracking $(b-\times 100)$

specimens with SC-cracks, cut out from the pipes of «Urengoy-Pomary-Uzhgorod» gas pipeline, failed in May, 2007. Similar failures on this gas pipeline were registered in May 2003 and in December 2007. In all described cases, SC-cracks and failures of gas pipeline were also oriented in longitudinal direction.

Local gas leakage and its ignition was detected during operation of main gas pipeline «Progress». Series of the through-wall defects was found in a zone of girth welded joints during test drilling of this section of gas pipeline. The girth weld in defective section was made by «tie-in» and it joints double-weld $1420 \mathrm{~mm}$ diameter pipe with $15.7 \mathrm{~mm}$ wall thickness of K60 strength class, manufactured at Khartsyzk Pipe Plant, to single-weld pipe of the same diameter with $15.4 \mathrm{~mm}$ wall thickness and X70 category of foreign delivery (Figure 5). Metal of both pipes was of similar chemical composition (the Table) and me-

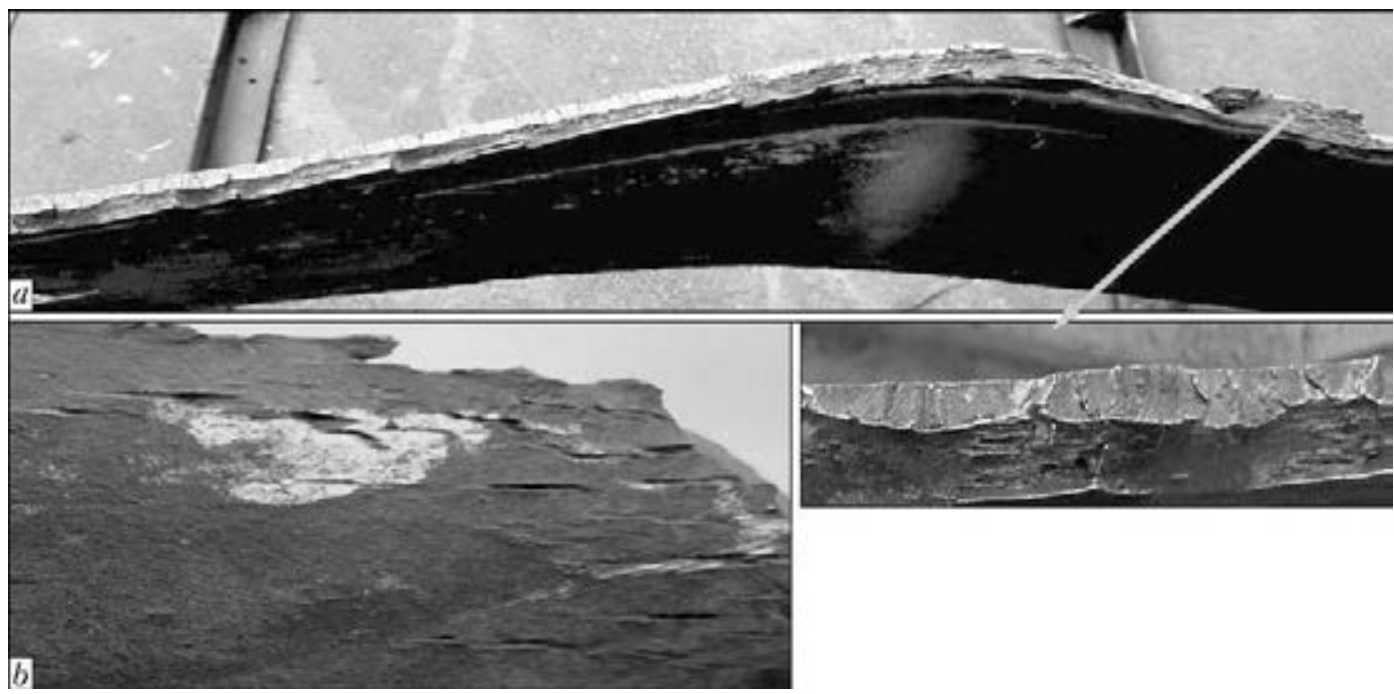

Figure 4. Fragments of failure of $1420 \mathrm{~mm}$ diameter gas pipeline with SC-cracks: $a$ - fracture of specimen with crack of $470 \mathrm{~mm}$ length and $6.8 \mathrm{~mm}$ depth; $b$ - colony of transverse macrocracks in zone of failure on pipe metal surface 
chanical properties. It can be assumed based on this that role of metallurgical factor in formation of these SC-cracks is minimum.

The pipeline in failure section was covered by strip polymeric insulation, which was damaged in the place of defect location.

Damage zone with crack-like defects (through-wall and surface ones) was located across the pipe axis and along the girth welded joint at around $800 \mathrm{~mm}$ length from both sides of the weld (Figure 6). Area of location of defective section in the girth joint on a route corresponded to $5-7 \mathrm{~h}$ of conventional dial. Width of the section with cracks, starting from the fusion line in direction of the base metal, made around $60 \mathrm{~mm}$ from each side of the weld.

Two different zones can be clearly observed on fracture of through-wall cracks after their opening, namely zone of defect formation from the side of external pipe surface, and zone of the final rupture on its internal side. Figure 7 shows fractures of the through-wall cracks in different sections. Failure surface in the crack zone has specific step nature, typical for defect, formed as a result of coalescence of smaller semi-elliptical cracks, nucleated in different, displaced relatively to each other, planes. Corrosion deposits are observed on the surface of cracks. The metal

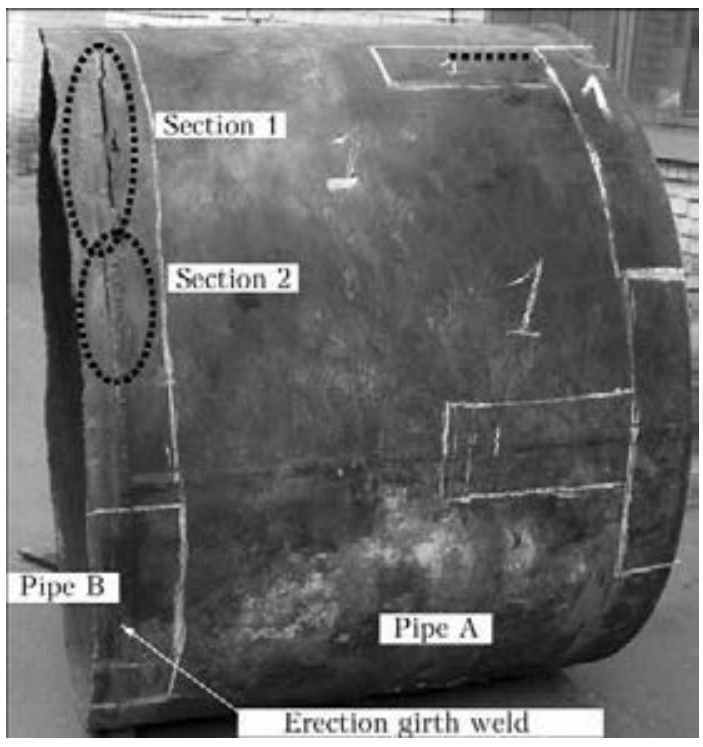

Figure 5. General appearance of failed erection girth joint and sections with maximum accumulation of cracks

in the zone of final rupture failures on tough mechanism.

External surface of both pipes nearby girth weld was damaged by relatively shallow corrosion spots and pitts that verify information about damage of insulation coating.

Multiple cracks of different depth, namely from surface ones to those passing through significant part of the wall thickness (Figure 8, $a$,

Chemical composition of pipe base metal, wt.\%

\begin{tabular}{|c|c|c|c|c|c|c|c|c|c|c|c|}
\hline $\begin{array}{c}\text { Place of } \\
\text { sampling }\end{array}$ & $\mathrm{C}$ & $\mathrm{Mn}$ & $\mathrm{Si}$ & $\mathrm{S}$ & $\mathrm{P}$ & $\mathrm{Al}$ & $\mathrm{Ni}$ & $\mathrm{Mo}$ & $\mathrm{Ti}$ & $\mathrm{V}$ & $\mathrm{Nb}$ \\
\hline Pipe A & 0.101 & 1.45 & 0.272 & 0.004 & 0.012 & 0.031 & 0.04 & 0.03 & 0.004 & 0.06 & 0.027 \\
\hline Pipe B & 0.119 & 1.48 & 0.357 & 0.003 & 0.016 & 0.034 & 0.05 & 0.03 & 0.005 & $<0.02$ & 0.028 \\
\hline
\end{tabular}
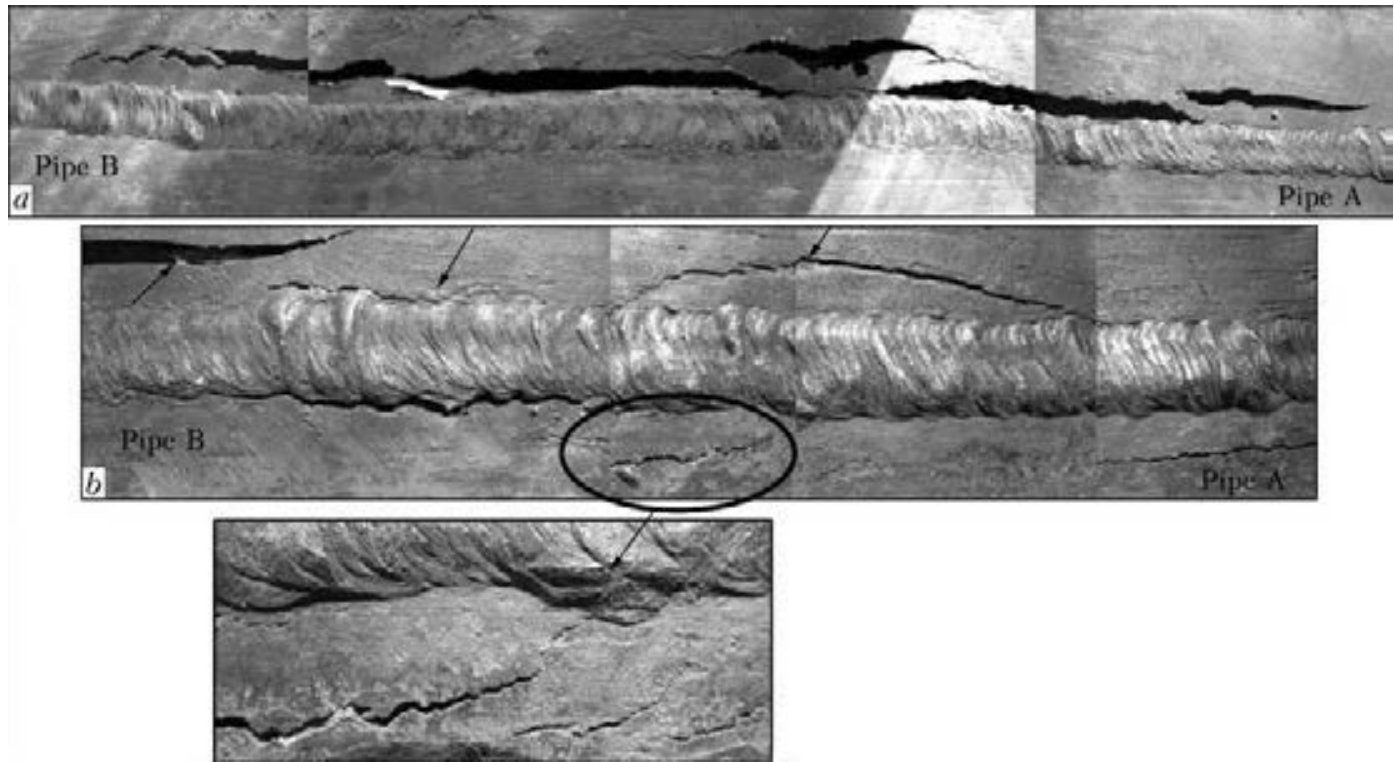

Figure 6. Sections of erection girth joint (see Figure 5) with maximum accumulation of cracks (arrows show crack location): $a, b-$ sections 1 and 2 , respectively 

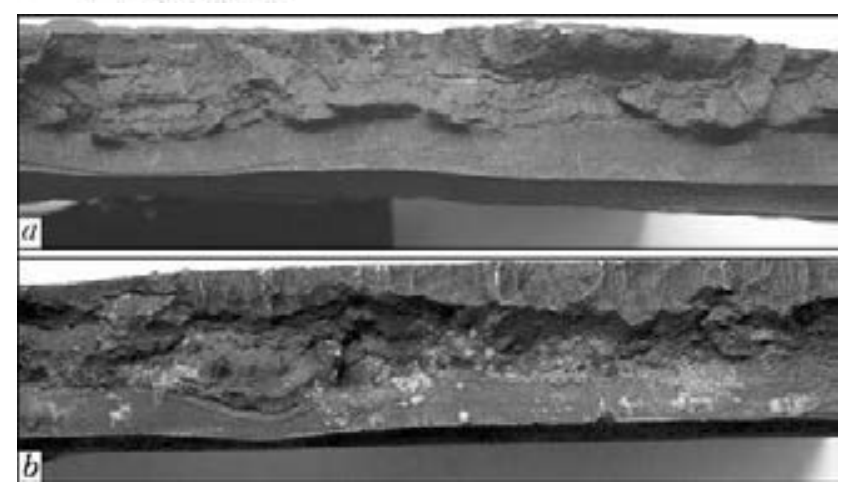

Figure 7. Nature of failure surface (through-wall crack)

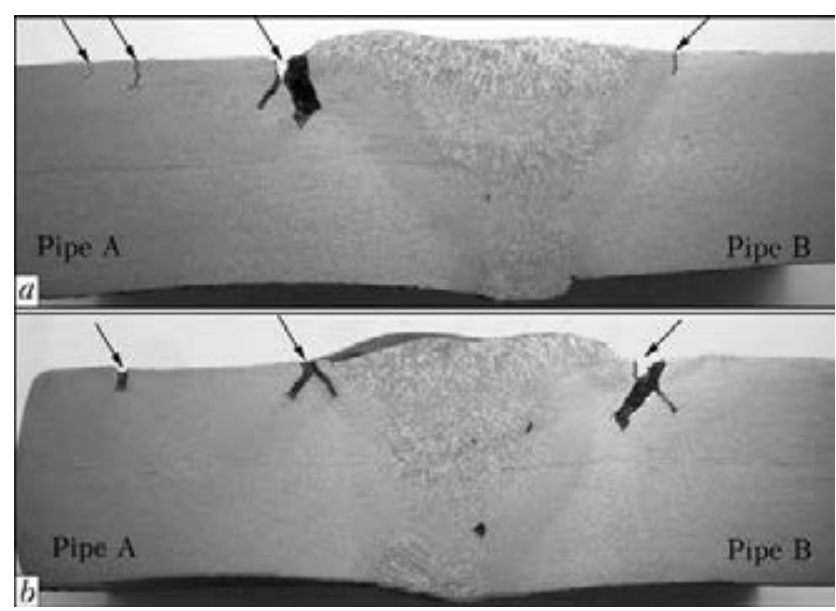

Figure 8. Transverse macrosections of girth welded joint in damage zone (location of cracks indicated by arrows)

$b)$ were registered in the metal of damaged zone of both pipes, as was shown by investigations of macro- and microsections. The cracks have relatively wide opening with rounded tips (see Figure $3, a)$. In the most cases, they are located along the girth weld in a plane normal to pipe generatrix or at around $45^{\circ}$.

Thus, the investigated defective section includes all the signs typical for SCC-failure of gas pipeline metal, i.e. presence of corrosion damages on the external surface of pipe metal, colonies of semi-elliptical cracks of different length and mainly with rounded tips and corrosion deposits, and step nature of fracture of the main cracks, giving evidence of process of coalescence of separate defects etc.

Girth weld of the studied joint was made by manual metal arc welding with some (maximum up to $2 \mathrm{~mm}$ ) displacement of pipe edges in radial direction, that does not exceed a limit set by SNiP III-42-80 (not more than $3 \mathrm{~mm}$ ). The girth weld from internal side of the pipe was parformed with significant lack of penetration of root layer up to $3 \mathrm{~mm}$ (it is well-known that no lack of

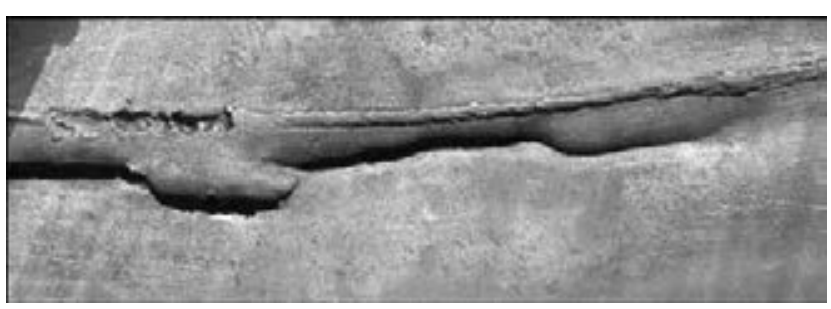

Figure 9. Internal surface of the pipe in damage zone

penetration of root part of erection weld in pipeline of $1000 \mathrm{~mm}$ diameter and more is allowed). At that, presence of indicated defects, in this case, was not exactly the reason of girth weld fracture.

It can be assumed that SCC-failure of girth welded joint of the gas pipeline, besides the corrosion factors, was promoted, to significant extent, by additional stresses, typical for process of pipe assembly during «tie-in» performance. It is indirectly verified by significant plastic strain of the metal in formation of through-wall defects, which can be seen in Figure 9 showing internal surface of the pipe in defective section.

Thus, the case was considered when SCC of the girth erection joint became the reason of main gas pipeline failure. Difference of this failure from the earlier investigated lies in SC-crack development in transverse direction relatively to the pipe axis.

In the authors' opinion, this information will be useful for the specialists working in oil-gas field during performance of diagnostic operations on the main gas pipelines.

1. (2006) Stress corrosion cracking of pipes of main pipelines: Atlas. Ed. by A.B. Arabej, Z. Knoshinsky. Moscow: Nauka.

2. Sutcliffe, J.M., Fessler, R.R., Boyd, W.K. et al. (1972) Stress corrosion cracking of carbon steel in carbonate solution. Corros. NASE, 28(8), 313-317.

3. Polyakov, S.G., Rybakov, A.A., Bekker, M.V. et al. (2004) Peculiarities of stress corrosion cracking of main pipelines. Fiz.-Khimich. Mekhanika Materialov, 4, 376-380.

4. Chviruk, V.P., Polyakov, S.G., Gerasimenko, Yu.S. (2007) Electrochemical monitoring of men-caused media. Kyiv: Akademperiodika.

5. Kryzhanivsky, E.I., Nykyforchyn, G.M. (2011) Corrosion-hydrogen degradation of oil-and-gas pipelines and its prevention: Manual. Vol. 1: Principles of evaluation of pipeline degradation. Ed. by V.V. Panasyuk. Ivano-Frankivsk: Iv.-Fr. NTUNG.

6. Eadie, R.L., Szklarz, R.E., Sutherby, R.L. (2005) Corrosion fatigue and near-neutral $\mathrm{pH}$ stress corrosion cracking of hydrogen sulfide. Corrosion, 61(2), 167-173.

7. Liu, Z.Y., Li, X.G., Du, C.W. et al. (2008) Stress corrosion cracking behavior of X70 pipe steel in an acidic soil environment. Corrosion Sci., 50(8), 2151-2257.

Received 08.11.2013 